\title{
Prevalence of abnormal kidney function in a rural population of Benin and associated risk factors
}

\author{
Gwladys N. Gbaguidi ${ }^{1,2^{*}}$ (D), Corine Y. Houehanou ${ }^{1,3}$, Salimanou A. Amidou', Jacques Vigan ${ }^{4}$, \\ Dismand S. Houinato ${ }^{1,2,5}$ and Philippe Lacroix ${ }^{2,6}$
}

\begin{abstract}
Background: The global burden of kidney disease has increased in recent years worldwide. Risk factors for kidney disease are common in Africa, but data on their prevalence are lacking. This study aims to determine the prevalence of abnormal kidney function and associated factors among participants included in the TAnve HEalth Study (TAHES) cohort in Benin.

Methods: This was a cross-sectional study nested within the TAHES cohort. It was carried out in 2019, among TAHE $S$ participants aged 25 years and above, living in Tanvè and Dékanmè, two villages located in southwestern Benin. Data on risk factors were collected using the World Health Organization's STEPS questionnaire. Anthropometric measurements and capillary creatinine measurements were performed. Abnormal kidney function was defined as a low glomerular filtration rate $(<60 \mathrm{~mL} / \mathrm{min} / 1.73 \mathrm{~m} 2)$.

Results: Creatinine was measured among 1360 out of the 1583 participants in the cohort in 2019. The median age was 39 [32-53]. The prevalence of abnormal kidney function was $16.10 \% ; 95 \% \mathrm{Cl}=[14.15-18.05]$. The results of the multivariate logistic regression showed that the probability of abnormal kidney function increased significantly with age (adjusted OR $(\mathrm{aOR})=2.75 ; 95 \% \mathrm{Cl}=[1.83-4.14])$, female gender $(\mathrm{aOR}=2 ; 95 \% \mathrm{Cl}=[1.37-2.91])$, hypertension $(\mathrm{aOR}=1.54 ; 95 \% \mathrm{Cl}=[1.12-$ $2.13])$, high body mass index $(\mathrm{aOR}=1,56 ; 95 \% \mathrm{Cl}=[1.12-2.17])$ and hyperglycemia $(\mathrm{aOR}=2.86 ; 95 \% \mathrm{Cl}=[1.68-4.88])$.

Conclusion: The prevalence of abnormal kidney function was high. These data should guide national authorities and help to raise community awareness of the benefits of early detection of this condition.
\end{abstract}

Keywords: Abnormal kidney function, Prevalence, Associated factors, Rural area, Benin

\section{Background}

The pattern of disease emergence in Sub-Saharan Africa (SSA) is changing, leading to an increase in noncommunicable diseases (NCDs) while infectious diseases already burden these countries [1]. The emergence of

\footnotetext{
* Correspondence: nadiagbaguidi@gmail.com

${ }^{1}$ Faculty of Health Sciences, Epidemiology Laboratory of Chronic and Neurologic Diseases, University of Abomey-Calavi, Cotonou, Benin ${ }^{2}$ INSERM, Univ. Limoges, CHU Limoges, IRD, U1094 Tropical

Neuroepidemiology, Institute of Epidemiology and Tropical Neurology, GEIST, 87000 Limoges, France

Full list of author information is available at the end of the article
}

NCDs in SSA reflects complex sociodemographic transitions characterized by improved survival into adulthood with relative aging of populations, rapid urbanization, and changes in diet, levels of activity, and habits such as increased smoking and alcohol consumption [1, 2]. Chronic kidney disease (CKD) is the final common pathway for many infections and NCDs, and is an independent risk factor for death from cardiovascular causes [3]. There is growing concern about the increase in its incidence and prevalence in recent years in developed and developing countries $[3,4]$. In 2016, the average

(c) The Author(s). 2021 Open Access This article is licensed under a Creative Commons Attribution 4.0 International License, which permits use, sharing, adaptation, distribution and reproduction in any medium or format, as long as you give appropriate credit to the original author(s) and the source, provide a link to the Creative Commons licence, and indicate if changes were made. The images or other third party material in this article are included in the article's Creative Commons licence, unless indicated otherwise in a credit line to the material. If material is not included in the article's Creative Commons licence and your intended use is not permitted by statutory regulation or exceeds the permitted use, you will need to obtain permission directly from the copyright holder. To view a copy of this licence, visit http://creativecommons.org/licenses/by/4.0/ The Creative Commons Public Domain Dedication waiver (http://creativecommons.org/publicdomain/zero/1.0/) applies to the data made available in this article, unless otherwise stated in a credit line to the data. 
prevalence of all stages of CKD was estimated at 13.4\% worldwide [5]. According to a meta-analysis that included 21 studies performed in SSA, the prevalence of CKD was estimated at $13.9 \%$ in 2014 [6].

Patients with CKD have a high risk of progression to end-stage renal disease (ESRD). The end-stage of this disease requires dialysis or kidney transplantation [7]. Although more than 2 million people worldwide need chronic kidney replacement therapy, only a minority of patients who have elevated risks of developing ESRD receive medical care [8]. CKD is a major public health challenge because the majority of people with the disease are neither detected nor adequately treated early [9]. The costs of ESRD management are very high, if not prohibitive, for the majority of the population. CKD worsens the quality of life and often leads to death. Early management of CKD could have a socio-economic benefit to the population and a country. Besides, cardiovascular risk factors (CVRFs) such as hypertension and diabetes are associated with CKD and are significantly growing in low- and middle-income countries (LMICs). Indeed, a $162.5 \%$ increase in the burden of diabetes and cardiovascular disease (CVD) is projected in SSA by 2045 [10].

The paucity of reliable population-based data on the prevalence of CKD in SSA was highlighted in two recent systematic reviews of CKD, with weaknesses in study design, laboratory methods for creatinine measurement, and the absence of standardized criteria for the definition of CKD being cited as reasons $[6,11]$. This could be an obstacle to the adoption of appropriate or adapted preventive measures. Early detection and intervention could prevent or reduce complications from kidney function alterations and could reduce the progression of kidney disease and the risk of CVD in the long term [12].

In Benin, STEPS survey conducted in 2015 showed the high prevalence's of several CVRFs in the adult Beninese population aged 24 to 65 years. More than a quarter of people surveyed had High Blood Pressure (HBP), and 4 $\%$ had raised blood glucose. The prevalence of HBP was high in urban and rural areas [13]. Very few studies have explored the frequency of CKD and its associated factors in the general population of Benin. Exploring the relevance of the proteinuria / creatinuria ratio in the screening of chronic renal disease, a study conducted in southern Benin found an altered glomerular filtration rate among 13 and $7 \%$ of participants in rural and urban areas, respectively [14]. Under these conditions of increasing in CVD, it is important to assess kidney function as accurately as possible because renal disease has different clinical presentations and patients are often asymptomatic [15]. In the current study, using data from the Benin cohort of the TAnve HEalth Study (TAHES), we determined population-based prevalence estimates of abnormal kidney function and studied its associated factors in a rural population.

\section{Methods}

\section{Study design and population}

This was a cross-sectional study including TAHES participants. The TAHES project is an ongoing prospective cohort that started in February 2015 with an annual follow-up using a door-to-door approach. The study is conducted in the villages of Tanvè and Dékanmè located in the Agbangnizoun district, in the southwest of Benin. All people aged 25 years and over and living in the two villages were included. Participants unable to respond were excluded [16]. Participants who did not have a creatinine result for technical measurement difficulty were excluded.

\section{Data collection}

Data were collected during a door-to-door survey conducted from 26 January to 17 February 2019 by seven previously trained investigative teams. The World Health Organization (WHO) STEPS questionnaire on NCD risk factors was used for the collection [17]. Sociodemographic and socio-economic information, personal and family cardiovascular medical history, lifestyle (physical activity, tobacco use, alcohol consumption, etc.), physical measurements (weight, height, waist circumference, hip circumference, blood pressure in both arms), and capillary blood glucose were collected. Capillary creatinine was collected in addition to the standard protocol.

\section{Creatinine measurement and abnormal kidney function definition}

Fasting blood creatinine levels were assessed using a portable analyzer (StatSensor Xpress Creatinine, Nova Biomedical, Waltham, MA, United States) with singleuse biosensors [18, 19]. To estimate the Glomerular Filtration Rate (eGFR), the Modification of Diet in Renal Disease (MDRD) study formula was used [20, 21]. The MDRD Study equation was expressed as follows: $175 \mathrm{x}$

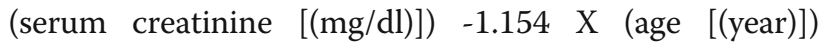
$-0.203 * 0.742$ (if female) * 1.21 (if black). Abnormal kidney function was defined as low eGFR (eGFR $<60 \mathrm{~mL} /$ $\min / 1.73 \mathrm{~m}^{2}$ ) [24].

Participants were also classified in five stages by eGFR level as follows [22]:

$$
\begin{aligned}
& \text { o Stage 1: eGFR } \geq 90 \mathrm{~mL} / \mathrm{min} / 1.73 \mathrm{~m}^{2} \\
& \text { - Stage 2: eGFR } 60-89 \mathrm{~mL} / \mathrm{min} / 1.73 \mathrm{~m}^{2} \\
& \text { o Stage 3: eGFR } 30-59 \mathrm{~mL} / \mathrm{min} / 1.73 \mathrm{~m}^{2} \\
& \text { o Stage 4: eGFR } 15-29 \mathrm{~mL} / \mathrm{min} / 1.73 \mathrm{~m}^{2} \\
& \text { o Stage 5: eGFR }<15 \mathrm{~mL} / \mathrm{min} / 1.73 \mathrm{~m}^{2}
\end{aligned}
$$




\section{Sociodemographic data}

Sociodemographic data included age, gender, education levels (illiterate, primary level, above primary level), marital status (in couple, single, widowed or divorced), occupation (independent farmer or informal, private or formal employee, unemployed), and the monthly income (<68 \$US, 68 \$US -179 \$US, $\geq 180$ \$US).

\section{Cardiovascular risk factor definitions}

Risk factors were defined according to the WHO STEPS manual [23]. Blood pressure was measured in both arms, using an electronic device (OMRON M3), with adequate cuffs for normal and large arms. It was measured three times at 5-min intervals, in a seated position after a rest of at least $15 \mathrm{~min}$. The average of the last two values was used to define blood pressure. HBP was defined as systolic and/or diastolic blood pressure $\geq 140 / 90 \mathrm{mmHg}$ in one of the two arms, or by currently receiving medication for hypertension. Hyperglycemia was defined as a fasting capillary blood glucose value $\geq 6.1 \mathrm{mmol} / \mathrm{L}$ or currently receiving diabetes medication. The Body Mass Index (BMI) was calculated as weight in kilograms divided by the square of the height in meters. High BMI was defined as BMI $\geq 25 \mathrm{~kg} / \mathrm{m}^{2}$.

\section{Statistical analysis}

The Shapiro-Wilk test was used to assess whether the quantitative variables were distributed in a normal mode. If so, mean and standard deviation (SD) were used as summary statistics and compared between two groups using the Student's test. If not, median and percentile were used and the Wilcoxon test performed for comparisons. Numbers and percentages were used for qualitative variables, and the chi-squared test was used for comparisons. A comparison of socio-demographic characteristics and CVRFs was conducted between participants with normal and abnormal kidney function in the study. The prevalence of abnormal kidney function has been estimated according to the MDRD equation. The different stages of eGFR have also been described. Univariate logistic regression models were performed to identify associations between kidney function and covariates. All variables that had $p$-values $<0.20$ in the univariate logistic regression model were introduced simultaneously in the multivariate model. Crude and adjusted odds ratios $(\mathrm{aOR})$ were estimated. In the sensitivity analysis, we estimated the prevalence of abnormal kidney function as well as the different stages of eGFR using the CKD-EPI formula. The threshold of significance was set at $p<0.05$. The analysis was performed by using $\mathrm{R}$ software (Version 3.6.1). We used crosssectional reporting guidelines (STROBE) for reporting this study [24].

\section{Results}

\section{Population characteristics}

A total of 1583 participants were included in the TAHE $\mathrm{S}$ cohort for the fourth annual follow-up survey in 2019. Among them, creatinine measurements were available for 1360 participants. There were 219 participants with eGFR deficiency (Fig. 1).

\section{Sample characteristics}

Table 1 presents the socio-demographic characteristics and the CVRFs comparison between participants with abnormal kidney function and those without. The median age of abnormal kidney function participants was 52 years, with an interquartile range of 38 to 66 years. The majority of abnormal kidney function participants were female. The prevalence of CVRFs in participants with abnormal kidney function was $47.5 \%$ for HBP, 37.4 for high BMI, and $11.9 \%$ for hyperglycemia.

\section{Prevalence of abnormal kidney function}

According the MDRD definition, the prevalence of abnormal kidney function was estimated at 16.1\%; (95\% Confidence Interval $(\mathrm{CI})=[14.1-18.1])$ with $14.4,1.6$ and $0.1 \%$ for stages 3,4 and 5 , respectively (Table 2).

\section{Associated factors}

Table 3 presents the associations between CVRFs, sociodemographic characteristics, and kidney function status. In the univariate analysis, only monthly income was not associated with abnormal kidney function $(p=0.229)$. Considering people aged $<60$ years as the reference group, the probability of having abnormal kidney function was significantly higher in the $\geq 60$-year-old group $(\mathrm{OR}=3.34 ; \quad 95 \% \mathrm{CI}=[2.41-4.63] ; \quad p<0.001)$. Females were more at risk for abnormal kidney function $(\mathrm{OR}=$ $2.04 ; 95 \% \mathrm{CI}=[1.46-2.84] ; p<0.001)$ than males. Primary school-level training was associated with a lower probability of abnormal kidney function $(\mathrm{OR}=0.67$; $95 \% \mathrm{CI}=[0.48-0.93] ; \quad p=0.022)$ compared to illiterate participants. Living alone increased the risk of abnormal kidney function $(\mathrm{OR}=2.63 ; \quad 95 \% \mathrm{CI}=[1.88-3.66]$; $p<0.001)$. The unemployed had significantly more risk for abnormal kidney function $(\mathrm{OR}=2.17 ; 95 \% \mathrm{CI}=$ [1.26-3.74]; $p=0.011)$ than self-employed farmers or people with informal occupations. Participants with HBP $(\mathrm{OR}=2.13 ; 95 \% \mathrm{CI}=[1.59-2.86] ; p<0.001)$, high $\mathrm{BMI}$ $(\mathrm{OR}=1.50,95 \% \mathrm{CI}=[1.11-2.03] ; \quad p=0.008)$ and those with hyperglycemia or under diabetes treatment $(\mathrm{OR}=$ $2.88,95 \% \mathrm{CI}=[1.75-4.73] ; p<0.001)$ respectively had significantly high risks of abnormal kidney function.

Results of the multivariable logistic regression showed that the probability of abnormal kidney function was significantly higher in the $\geq 60$ year-old age group than in the $<60$ year-old age group $(\mathrm{aOR}=2.75 ; 95 \% \mathrm{CI}=[1.73-$ 


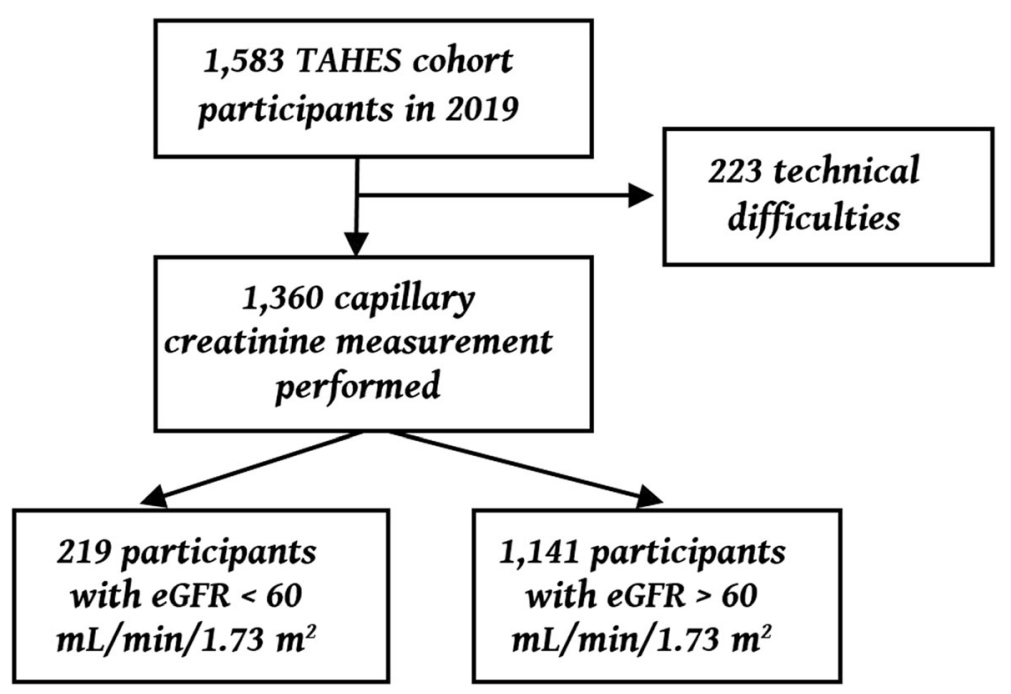

Fig. 1 Flowchart of inclusion in this study population from the TAHES cohort, 2019

Table 1 Socio-demographic characteristics and CVRFs for study participants according to the state of renal function, TAHES study, Benin 2019

\begin{tabular}{|c|c|c|c|}
\hline & Abnormal kidney function $(n=219)$ & Normal kidney function $(n=1141)$ & $p$ - \\
\hline & Median [Q1-Q3] / n (\%) & Median [Q1-Q3] / n (\%) & \\
\hline Age (years) & $52[38-66]$ & $39[31-50]$ & $<0.001$ \\
\hline Age ( $\geq 60$ years) & $76(34.7)$ & $157(13.8)$ & $<0.001$ \\
\hline Gender & & & \\
\hline Male & $52(23.7)$ & $443(38.8)$ & $<0.001$ \\
\hline Education levels & & & \\
\hline Illiterate & $158(72.1)$ & $715(62.7)$ & 0.025 \\
\hline Primary level & $52(23.7)$ & $353(30.9)$ & \\
\hline Above primary level & $9(4.1)$ & $73(6.4)$ & \\
\hline Marital status & & & \\
\hline In couple & $153(69.9)$ & $980(85.9)$ & $<0.001$ \\
\hline Single, widowed or divorced & $66(30.1)$ & $161(14.1)$ & \\
\hline Occupation & & & \\
\hline Independent farmer or informal $^{a}$ & $179(81.7)$ & $951(83.3)$ & 0.006 \\
\hline Private or formal employee & $20(9.1)$ & $141(12.4)$ & \\
\hline Unemployed $^{\mathrm{b}}$ & $20(9.1)$ & $49(4.3)$ & \\
\hline Monthly income (\$US) & & & \\
\hline$<68$ & $95(43.4)$ & $461(40.4)$ & 0.245 \\
\hline $68-179$ & $90(41.1)$ & $447(39.2)$ & \\
\hline$\geq 180$ & $34(15.5)$ & $233(20.4)$ & \\
\hline HBP & $104(47.5)$ & $340(29.8)$ & $<0.001$ \\
\hline High BMI ${ }^{c}$ & $82(37.4)$ & $325(28.5)$ & 0.010 \\
\hline Hyperglycemia $^{d} /$ Diabetes Treatment $^{e}$ & $26(11.9)$ & $51(4.5)$ & $<0.001$ \\
\hline
\end{tabular}


Table 2 Prevalence of abnormal kidney function and classification of eGFR according to the MDRD equation, TAHES Study, Benin 2019

\begin{tabular}{lll}
\hline eGFR by stages $\left(\mathrm{eGFR}\right.$ in $\left.\mathbf{~} \mathrm{L} / \mathrm{min} / \mathbf{1 . 7 3} \mathbf{~ m}^{\mathbf{2}}\right)$ & $\mathbf{n = 1 3 6 0}$ & $\mathbf{( \% )}$ \\
\hline $\begin{array}{l}\text { Overall prevalence }(\mathrm{eGFR}<\mathbf{6 0}) \\
\text { eGFR by stages }\end{array}$ & $\mathbf{2 1 9}$ & $\mathbf{1 6 . 1}[\mathbf{1 4 . 1 - 1 8 . 1 ]}$ \\
$\quad$ Stage $1(\mathrm{eGFR} \geq 90)$ & 452 & 33.2 \\
Stage $2(\mathrm{eGFR}=60-89)$ & 689 & 50.7 \\
Stage $3(\mathrm{eGFR}=30-59)$ & 196 & 14.4 \\
Stage $4(\mathrm{eGFR}=15-29)$ & 22 & 1.6 \\
Stage $5(\mathrm{eGFR}<15)$ & 1 & 0.1 \\
\hline
\end{tabular}

3.83]; $p<0.001)$. Women had a higher risk for abnormal kidney function than men $(\mathrm{aOR}=1.98 ; 95 \% \mathrm{CI}=[1.36-$ 2.89]; $p<0.001$ ). The probability of abnormal kidney function was significantly higher among participants with $\mathrm{HBP}(\mathrm{aOR}=1.56 ; 95 \% \mathrm{CI}=[1.13-2.15] ; p=0.007)$, participants with high $\mathrm{BMI}(\mathrm{aOR}=1.56 ; 95 \% \mathrm{CI}=[1.12-$ 2.17]; $p=0.009)$ and in participants with hyperglycemia or diabetes $(\mathrm{aOR}=2.88 ; 95 \% \mathrm{CI}=[1.68-4.92] ; p<0.001)$ than among those without.

\section{Sensitivity analysis}

By using the CKD-EPI equation, the estimated prevalence of abnormal kidney function was slightly lower $(14.1 \%$; CI $95 \%=[12.25-15.95])$. This prevalence was

Table 3 Factors associated with abnormal kidney function, TAHES Study, Benin 2019

\begin{tabular}{|c|c|c|c|c|}
\hline & \multicolumn{2}{|c|}{$\begin{array}{l}\text { Univariate analysis } \\
n=1360\end{array}$} & \multicolumn{2}{|c|}{$\begin{array}{l}\text { Multivariate analysis } \\
n=1359\end{array}$} \\
\hline & OR $(95 \% \mathrm{Cl})$ & $P$ value ${ }^{*}$ & aOR $(95 \% \mathrm{Cl})$ & $P$ value \\
\hline Age (> 60 years) & $3.34(2.41,4.63)$ & $<0.001$ & $2.57(1.73,3.83)$ & $<0.001$ \\
\hline \multicolumn{5}{|l|}{ Gender } \\
\hline Male & 1 & & 1 & \\
\hline Female & $2.04(1.46,2.84)$ & $<0.001$ & $1.98(1.36,2.89)$ & $<0.001$ \\
\hline Level of education & & 0.022 & & 0.95 \\
\hline Illiterate & 1 & & 1 & \\
\hline Primary level & $0.67(0.48,0.93)$ & & $1.06(0.72,1.54)$ & \\
\hline Above primary level & $0.56(0.27,1.14)$ & & $1.09(0.49,2.43)$ & \\
\hline \multicolumn{5}{|l|}{ Marital status } \\
\hline In couple & 1 & & & \\
\hline Single, widowed or divorced & $2.63(1.88,3.66)$ & $<0.001$ & $1.42(0.95,2.13)$ & 0.091 \\
\hline Occupation & & 0.011 & & 0.278 \\
\hline Independent farmer or informal & 1 & & & \\
\hline Private or formal employee & $0.75(0.46,1.24)$ & & $0.73(0.43,1.26)$ & \\
\hline Unemployed & $2.17(1.26,3.74)$ & & $1.36(0.73,2.51)$ & \\
\hline Monthly income (\$US) & & 0.229 & & \\
\hline$<68$ & 1 & & & \\
\hline $68-179$ & $0.98(0.71,1.34)$ & & & \\
\hline$\geq 180$ & $0.71(0.46,1.08)$ & & & \\
\hline HBP & $2.13(1.59,2.86)$ & $<0.001$ & $1.56(1.13,2.15)$ & 0.007 \\
\hline High BMI $^{\mathrm{a}}$ & $1.50(1.11,2.03)$ & 0.008 & $1.56(1.12,2.17)$ & 0.009 \\
\hline Hyperglycemia $^{b}$ / diabetes treatment & $2.88(1.75,4.73)$ & $<0.001$ & $2.88(1.68,4.92)$ & $<0.001$ \\
\hline
\end{tabular}

${ }^{*} p$ value of Wald test for binary variables or likelihood test for categorical variables with more than two modalities

${ }^{a}$ High BMI (BMI $\left.\geq 25 \mathrm{~kg} / \mathrm{m} 2\right)$

${ }^{\text {b }}$ Hyperglycemia capillary blood glucose $\geq 6.1 \mathrm{mmol} / \mathrm{L}$ 
$12.4,1.7$, and $0.1 \%$ for the moderate, severe, and terminal stages, respectively (Table 4).

\section{Discussion}

Using low eGFR to define abnormal kidney function, we showed a prevalence of $16.1 \%$. This could be explained by the large burden of CVRFs among our study participants $(32.6 \%$ for HBP, $29.9 \%$ for high BMI, $5.7 \%$ for hyperglycemia). Our results are consistent with the worldwide range of fluctuations for CKD prevalence 8$16 \%$ [25]. However, this is higher than the CKD prevalence reported in previous studies conducted by Okwuonu et al. in Nigeria, Sumaili et al. in the Democratic Republic of Congo and Adeniyi et al. in South Africa, with prevalence rates of $7.8,12.4$, and $6.1 \%$, respectively $[4,26,27]$. These low CKD prevalence rates could be explained by the population's characteristics and differences in CKD measurements. Indeed, Okwuonu et al. in their study repeated the measurement of creatinine 3 months later. This certainly allowed them to obtain a better estimate of the prevalence of chronic kidney disease, unlike our study in which this measurement was only taken once. The South African study conducted by Matsha et al. found a CKD prevalence of $23.9 \%$ using the MDRD equation and $17.3 \%$ using the CKD-EPI in a mixed-ethnicity community in the city of Cape Town [28]. This estimation is higher than ours and could be explained by the fact that their study population was older ( 52.9 years old on average), had a high proportion of diabetics (26.4\%) and smokers (40.5\%).

We noted that the probability of abnormal kidney function increased significantly with age. Other studies have described such an association [29,30]. This could be explained by the pathophysiological mechanisms, a decline in vital functions, and the increase in the prevalence of CVRFs with increasing age.

In our study, the risk of abnormal kidney function was also twice as high in women as in men. Similar observations were also made in several other studies [7, 31, 32]. This could be explained by our study population, which

Table 4 Prevalence of abnormal kidney function and classification of eGFR according to CKD Epi equation, TAHES Study, Benin 2019

\begin{tabular}{|c|c|c|}
\hline $\begin{array}{l}\text { eGFR by stages } \\
\left(\mathrm{eGFR} \text { in } \mathrm{mL} / \mathrm{min} / 1.73 \mathrm{~m}^{2}\right)\end{array}$ & $n=1360$ & (\%) \\
\hline Overall prevalence $(e G F R<60)$ & 192 & $14.1[12.25-15.95]$ \\
\hline \multicolumn{3}{|l|}{ eGFR by stages } \\
\hline Stage 1 (eGFR $\geq 90$ ) & 567 & 41.7 \\
\hline Stage $2(e G F R=60-89)$ & 601 & 44.2 \\
\hline Stage 3 (eGFR = 30-59) & 168 & 12.4 \\
\hline Stage $4(\mathrm{eGFR}=15-29)$ & 23 & 1.7 \\
\hline Stage 5 (eGFR < 15) & 1 & 0.1 \\
\hline
\end{tabular}

is more female, and by the average age of the participants with abnormal kidney function, which is relatively high in our study.

The difference in glomerular structure and hormone metabolism and the fact that females have less muscle mass than males are believed to play a major role in the differences in the prevalence of CKD between females and males [33, 34]. In contrast, some studies have shown that the incidence of CKD is lower in women than in men and that the decline in kidney function is slower in women than in men $[29,35,36]$. It has been shown that men consume more salt, phosphorus, and protein, and are more often obese and/or hypertensive [35]. These factors contribute to but do not fully explain the difference. Animal studies suggest that estrogens are nephroprotective and androgens are nephrotoxic. In humans, this subject has not yet been sufficiently studied and needs to be further investigated [34]. Adjusted for age and gender, CVRFs such as HBP, high BMI, and hyperglycemia or diabetes, were associated with a higher risk of abnormal kidney function. The relation between CKD and CVRFs such as hypertension and diabetes has been demonstrated in several studies [4,30,31]. Like other LMICs, the prevalence of hypertension is increasing in Benin [37]. According to the WHO STEPS survey conducted in Benin in 2015, the prevalence of hypertension was $26 \%$ with an almost identical distribution between rural and urban areas [38]. According to the previous study, in this cohort, $42 \%$ of hypertensive people were aware of their hypertensive condition and only $46.3 \%$ of them were treated [16]. This poor management of HBP could induce consequences for other organs, including the kidney. Concerning diabetes, in 2019, SSA had the lowest age-standardized global prevalence of diabetes in the world (4.7\%). According to the International Diabetes Federation, however, this region has the highest proportion of undiagnosed diabetes cases (66.8\%) [39]. Untreated or poorly treated, diabetes has serious consequences on several organs, including the kidneys. Hyperglycemia induces hyperfiltration and morphological alterations in the kidneys, which then leads to excessive excretion of albumin in the urine (albuminuria), damage to the podocytes, and loss of the surface area of the kidney $[40,41]$.

As the metabolic syndromes could be consequences of the combination of CVRFs, kidney dysfunction is also a real concern. The diagnosis and effective treatment of the early stages of kidney disease is especially important in Africa and other LMIC environments because the options for treating late complications such as ESRD are very limited or unavailable. This is in contrast to highincome countries where dialysis or transplantation is available to many patients who require these expensive therapies. Screening programs dedicated to individuals 
at higher risk of developing kidney disease (those with diabetes, with HBP) must be promoted.

\section{Strength and limits of the study}

The prevalence of abnormal kidney function may be overestimated because creatinemia was measured only once. The delay of abnormality was not known and the persistence of the abnormality could not be established. A Moroccan study that repeated creatinine measurements showed that $32 \%$ of stage 3 CKD patients in the initial test did not have a low eGFR on retesting [42]. Using the single creatinine threshold to define a low eGFR could overdiagnose the prevalence of the disease. The cross-sectional design of our study does not allow us to establish the causal relationship between abnormal kidney function and CVRFs. Also, our study did not include urine protein/albumin measurements. These tests could help refine the diagnosis of renal dysfunction. As the TAHES cohort is still ongoing, in future follow-up surveys we plan to perform repeated creatinine tests and additional measurements for albumin in urine. These supplemental measures will contribute to improving the data on renal function impairment and will provide accurate diagnosis/information on the presence of CKD in the population. We also have a potential residual confusion bias. Indeed, the use of drugs (antibiotics, NSAIDs), the use of herbal medicine and the presence of systemic infections were not evaluated in this study. Therefore, these factors may have led to underestimating or overestimating the strength of association of certain factors such as hypertension. It would be relevant to consider these factors in further study. Some participants in TAHES were not included in the study due to technical difficulties during creatinine measurement. This could introduce potential selection bias in our study. The distribution of important risk factors such as hypertension and hyperglycemia, however, was not different between the participants included and those excluded for failure to measure creatinine. The single-point measurement of high blood pressure and hyperglycemia is also a limitation of our study as it could lead to an overestimation of their prevalence.

Despite these limitations, our study remains the largest study conducted in a large general population in SSA. This study has enabled us to estimate the prevalence of CKD using a rigorous, standardized evaluation methodology. This is the first study conducted in rural Benin on a large population with exhaustive recruitment of the study population. The assessment of capillary creatinine was carried out using a creatinine tester and strips. This could limit the potential measure bias.

\section{Conclusion}

This study carried out on a large rural population in Benin shows that the prevalence of abnormal kidney function was high in this population. Abnormal kidney function is associated with the presence of HBP and blood glucose levels, disorders that are often unrecognized and rarely controlled in this population. These data support the development of interventions for the prevention and early detection of these risk factors. Repeating the creatinine measurements and taking into account the limitations of this study could provide a better estimate of the prevalence of chronic kidney disease in this population.

\section{Abbreviations}

aOR: Adjusted Odd Ratios; BMI: Body Mass Index; CKD: Chronic Kidney Disease; CVD: Cardiovascular Disease; CVRFs: Cardiovascular Risk Factors; eGFR: Glomerular Filtration Rate; ESRD: End-Stage Renal Disease; HBP: High blood pressure; LMIC: Low-and Middle-Income Countries;

MDRD: Modification of Diet in Renal Disease; NCD: Non-Communicable Diseases; SSA: Sub-Saharan Africa; SD: standard deviation; TAHES: TAnve HEalth Study; WHO: World Health Organization

\section{Acknowledgements}

The authors thank Auriane Adjahouhoue, Concheta Tchibozo, and Edmond Echissè for the quality of their daily work on TAHES. Thanks also to the participants in this survey, the regional health directorate of Zou, the Mayor of Agbangnizoun and his staff, the village of Tanve's chief ministry and the community health workers in Tanve.

\section{Authors' contributions}

GNG, CYH, SAA, DSH and PL contributed for conception and design: Acquisition of data: GNG, CYH, SAA, DSH, PL; Statistical analysis: GNG; Data Interpretation: All authors; Drafting of the manuscript: GNG; Critical revision of the manuscript for important intellectual content: All authors; Obtaining funding: DSH, PL; Supervision: DSH, PL. We confirm that the manuscript has been read and approved for submission by all named authors.

\section{Funding}

This survey was supported by the FRHTA Foundation, Paris, France. The sponsors had no role in the design, methods, participants recruitment, data collection, analysis, or preparation of this manuscript.

\section{Availability of data and materials}

The data that support the findings of this study are available from DSH and PL but restrictions apply to the availability of these data, which were used under license for the current study and so are not publicly available. Data are, however, available from the authors upon reasonable request and with permission from DSH and PL.

\section{Declarations}

Ethics approval and consent to participate

The TAHES protocol received approval No. 026 of August 28, 2014, from the National Committee of Ethics for Health Research (CNERS) of the Ministry of Health of Benin. Informed and written consent was required for each participant before inclusion in TAHES. Furthermore, participants with abnormal creatinine values were examined by a physician recruited for the study. Following their examinations, they received counseling, prescription drugs and were referred to the Abomey municipal health center for further exams or the regional hospital for nephrological consultation, depending on the participant's situation.

Consent for publication

Not Applicable.

Competing interests

All the authors declared no competing interests. 


\section{Author details}

${ }^{1}$ Faculty of Health Sciences, Epidemiology Laboratory of Chronic and Neurologic Diseases, University of Abomey-Calavi, Cotonou, Benin. ${ }^{2}$ INSERM, Univ. Limoges, CHU Limoges, IRD, U1094 Tropical Neuroepidemiology, Institute of Epidemiology and Tropical Neurology, GEIST, 87000 Limoges, France. ${ }^{3}$ ENATSE, University of Parakou, Parakou, Benin. ${ }^{4}$ Nephrology Unit, $\mathrm{CNHU}$ Cotonou, Cotonou, Benin. ${ }^{5}$ Neurology Unit, CNHU Cotonou, Cotonou, Benin. ${ }^{6}$ Department of Vascular Medicine, CHU Limoges, 87000 Limoges, France.

\section{Received: 5 August 2020 Accepted: 22 March 2021} Published online: 31 March 2021

\section{References}

1. Mudie K, Jin MM, Tan, Kendall L, Addo J, dos Santos-Silva I, et al. Noncommunicable diseases in sub-Saharan Africa: a scoping review of large cohort studies. J Glob Health. 2019;9:020409. https://doi.org/10.7189/jogh.09. 020409

2. Bigna JJ, Noubiap JJ. The rising burden of non-communicable diseases in sub-Saharan Africa. Lancet Glob Health. 2019;7(10):e1295-6. https://doi.org/1 0.1016/S2214-109X(19)30370-5.

3. George JA, Brandenburg J-T, Fabian J, Crowther NJ, Agongo G, Alberts M, et al. Kidney damage and associated risk factors in rural and urban subSaharan Africa (AWl-gen): a cross-sectional population study. Lancet Glob Health. 2019;7(12):e1632-43. https://doi.org/10.1016/S2214-109X(19)30443-7.

4. Okwuonu CG, Chukwuonye II, Adejumo OA, Agaba El, Ojogwu LI. Prevalence of chronic kidney disease and its risk factors among adults in a semi-urban community of South-East Nigeria. Niger Postgrad Med J. 2017; 24(2):81-7. https://doi.org/10.4103/npmj.npmj_34_17.

5. Hill NR, Fatoba ST, Oke JL, Hirst JA, O'Callaghan CA, Lasserson DS, et al. Global prevalence of chronic kidney disease - a systematic review and meta-analysis. PLoS One. 2016;11(7):e0158765. https://doi.org/10.1371/journa I.pone.0158765.

6. Stanifer JW, Jing B, Tolan S, Helmke N, Mukerjee R, Naicker S, et al. The epidemiology of chronic kidney disease in sub-Saharan Africa: a systematic review and meta-analysis. Lancet Glob Health. 2014;2(3):e174-81. https://doi. org/10.1016/S2214-109X(14)70002-6.

7. Chukwuonye II, Ohagwu KA, Adelowo OO, Chuku A, Obi EC, Onwuchekwa $U$, et al. Prevalence and predictors of chronic kidney disease in a Semiurban Community in Lagos. Int J Nephrol. 2019;2019:1-6. https://doi.org/10.1155/2 019/1625837.

8. Couser WG, Remuzzi G, Mendis S, Tonelli M. The contribution of chronic kidney disease to the global burden of major noncommunicable diseases. Kidney Int. 2011;80(12):1258-70. https://doi.org/10.1038/ki.2011.368.

9. Atkins RC. The epidemiology of chronic kidney disease. Kidney Int Suppl. 2005;67(94):S14-18.

10. International Diabetes Federation. IDF DIABETES ATLAS : Eighth edition 2017. 2017. https://www.diabetesatlas.org/upload/resources/previous/files/8/ IDF_DA_8e-EN-final.pdf.

11. ElHafeez SA, Bolignano D, D’Arrigo G, Dounousi E, Tripepi G, Zoccali C. Prevalence and burden of chronic kidney disease among the general population and high-risk groups in Africa: a systematic review. BMJ Open. 2018;8(1):e015069. https://doi.org/10.1136/bmjopen-2016-015069.

12. Levey AS, Schoolwerth AC, Burrows NR, Williams DE, Stith KR, McClellan W Comprehensive public health strategies for preventing the development, progression, and complications of CKD: report of an expert panel convened by the Centers for Disease Control and Prevention. Am J Kidney Dis. 2009; 53(3):522-35. https://doi.org/10.1053/j.ajkd.2008.11.019.

13. Houehanou YCN, Lacroix P. Mizehoun GC, Preux P-M, Marin B, Houinato DS. Magnitude of cardiovascular risk factors in rural and urban areas in Benin: findings from a Nationwide Steps survey. PLoS One. 2015;10(5):e0126441. https://doi.org/10.1371/journal.pone.0126441.

14. Agboton BL, Aguemon B, Vigan J, Oke YJ, Ahoui S, Djrolo F, et al. Prévalence de la maladie rénale chronique et des facteurs associés au sud du Bénin : intérêt du rapport protéinurie/créatinurie. In: Néphrologie \& thérapeutique; 2017. p. 395. https://doi.org/10.1016/j.nephro.2017.08.300.

15. Jungers P. Screening for renal insufficiency: is it worth while? Is it feasible? Nephrol Dial Transplant. 1999;14(9):2082-4. https://doi.org/10.1093/ndt/14. 9.2082.

16. Desormais I, Amidou SA, Houehanou YC, Houinato SD, Gbagouidi GN, Preux PM, et al. The prevalence, awareness, management and control of hypertension in men and women in Benin, West Africa: the TAHES study. BMC Cardiovasc Disord. 2019;19:303.

17. World Health Organization. WHO STEPS surveillance manual : the WHO STEPwise approach to chronic disease risk factor surveillance: World Health Organization; 2005. https://apps.who.int/iris/handle/10665/43376. Accessed 17 Mar 2021

18. Kosack CS, de Kieviet W, Bayrak K, Milovic A, Page AL. Evaluation of the Nova StatSensor ${ }^{\oplus}$ XpressTM creatinine point-of-care handheld analyzer. PLoS One. 2015;10(4):e0122433. https://doi.org/10.1371/journal.pone. 0122433.

19. Srihong C, Pangsapa K, Chuaboonmee K, Kotipan Y, Charuruks N. Evaluation of the analytical performance of the nova StatSensor creatinine meter for blood testing. J Med Assoc Thail. 2012;95:1225-31.

20. Levey AS, Coresh J, Greene T, Stevens LA, Zhang YL, Hendriksen S, et al. Using standardized serum creatinine values in the modification of diet in renal disease study equation for estimating glomerular filtration rate. Ann Intern Med. 2006;145(4):247-54. https://doi.org/10.7326/0003-4819-145-4-2 00608150-00004.

21. Levey AS. A more accurate method to estimate glomerular filtration rate from serum creatinine: a new prediction equation. Ann Intern Med. 1999; 130(6):461. https://doi.org/10.7326/0003-4819-130-6-199903160-00002.

22. Levey AS, Eckardt K-U, Tsukamoto Y, Levin A, Coresh J, Rossert J, et al. Definition and classification of chronic kidney disease: a position statement from kidney disease: improving global outcomes (KDIGO). Kidney Int. 2005; 67(6):2089-100. https://doi.org/10.1111/j.1523-1755.2005.00365.x.

23. Cluster WHOND and MH. WHO STEPS stroke manual: the WHO STEPwise approach to stroke surveillance: World Health Organization; 2005. https://a pps.who.int/iris/handle/10665/43420. Accessed 30 Apr 2020

24. von Elm E, Altman DG, Egger M, Pocock SJ, Gøtzsche PC, Vandenbroucke $J P$, et al. The strengthening the reporting of observational studies in epidemiology (STROBE) statement: guidelines for reporting observational studies. J Clin Epidemiol. 2008;61(4):344-9. https://doi.org/10.1016/j.jclinepi.2 007.11.008,

25. Jha V, Garcia-Garcia G, Iseki K, Li Z, Naicker S, Plattner B, et al. Chronic kidney disease: global dimension and perspectives. Lancet. 2013;382(9888): 260-72. https://doi.org/10.1016/S0140-6736(13)60687-X.

26. Adeniyi $A B$, Laurence CE, Volmink JA, Davids MR. Prevalence of chronic kidney disease and association with cardiovascular risk factors among teachers in Cape Town, South Africa. Clin Kidney J. 2017;10:363-9.

27. Sumaili EK, Krzesinski J-M, Zinga CV, Cohen EP, Delanaye P, Munyanga SM, et al. Prevalence of chronic kidney disease in Kinshasa: results of a pilot study from the Democratic Republic of Congo. Nephrol Dial Transplant. 2009;24:117-22.

28. Matsha TE, Yako YY, Rensburg MA, Hassan MS, Kengne AP, Erasmus RT. Chronic kidney diseases in mixed ancestry south African populations: prevalence, determinants and concordance between kidney function estimators. BMC Nephrol. 2013;14(1):75. https://doi.org/10.1186/1471-23 69-14-75.

29. Collins AJ, Gilbertson DT, Snyder JJ, Chen S-C, Foley RN. Chronic kidney disease awareness, screening and prevention: rationale for the design of a public education program. Nephrology (Carlton). 2010;15(Suppl 2):37-42. https://doi.org/10.1111/j.1440-1797.2010.01312.x.

30. Alkerwi A, Sauvageot N, El Bahi I, Delagardelle C, Beissel J, Noppe S, et al. Prevalence and related risk factors of chronic kidney disease among adults in Luxembourg: evidence from the observation of cardiovascular risk factors (ORISCAV-LUX) study. BMC Nephrol. 2017;18(1):358. https://doi.org/10.1186/ s12882-017-0772-6.

31. Zhang L, Wang Z, Chen Y, Wang X, Chen Z, Feng B, et al. Prevalence and risk factors associated with chronic kidney disease in adults living in 3 different altitude regions in the Tibetan plateau. Clin Chim Acta. 2018;481: 212-7. https://doi.org/10.1016/j.cca.2018.03.025.

32. Zhang Q- L, Rothenbacher D. Prevalence of chronic kidney disease in population-based studies: systematic review. BMC Public Health. 2008;8(1): 117. https://doi.org/10.1186/1471-2458-8-117.

33. Hecking M, Bieber BA, Ethier J, Kautzky-Willer A, Sunder-Plassmann G, Säemann MD, et al. Sex-specific differences in hemodialysis prevalence and practices and the male-to-female mortality rate: the dialysis outcomes and practice patterns study (DOPPS). PLoS Med. 2014;11(10):e1001750. https:// doi.org/10.1371/journal.pmed.1001750. 
34. Levey AS, Stevens LA, Schmid CH, Zhang Y, Castro AF, Feldman HI, et al. A new equation to estimate glomerular filtration rate. Ann Intern Med. 2009. 150(9):604-12. https://doi.org/10.7326/0003-4819-150-9-200905050-00006.

35. Michel PM, Menno Pruijm B. Inégalité homme-femme face aux maladies rénales chroniques: mythe ou réalité ? Rev Méd Suisse. 2017;13:473-6.

36. Berg UB. Differences in decline in GFR with age between males and females. Reference data on clearances of inulin and PAH in potential kidney donors. Nephrol Dial Transplant. 2006;21(9):2577-82. https://doi.org/10.1093/ $n d t / g f l 227$.

37. Houinato DS, Gbary AR, Houehanou YC, Djrolo F, Amoussou M, SegnonAgueh J, et al. Prevalence of hypertension and associated risk factors in Benin. Rev Epidemiol Sante Publique. 2012;60(2):95-102. https://doi.org/10.1 016/j.respe.2011.09.010

38. Programme National de Lutte contre les Maladies Non Transmissibles du Bénin. Rapport final de l'enquête pour la surveillance des facteurs de risque des maladies non transmissibles par l'approche STEPSwise" de l'OMS ENQUETE STEPS 2015" au Bénin. 2016. https://www.who.int/ncds/surveilla nce/steps/Benin_2015_STEPS_Report_FR.pdf. Accessed 29 Mar 2020.

39. International Diabetes Federation. IDF DIABETES ATLAS Ninth edition 2019. 2019. https://diabetesatlas.org/fr/resources/. Accessed 27 Mar 2020.

40. Pavkov ME, Collins AJ, Coresh J, Nelon RG. Kidney disease in diabetes. In: Diabetes in America. 3rd ed: National Institute of Diabetes and Digestive and Kidney Diseases; 2021. p. 84.

41. Fakhruddin S, Alanazi W, Jackson KE. Diabetes-induced reactive oxygen species: mechanism of their generation and role in renal injury. J Diabetes Res. 2017:2017:8379327.

42. Benghanem Gharbi M, Elseviers M, Zamd M, Belghiti Alaoui A, Benahadi N, Trabelssi EH, et al. Chronic kidney disease, hypertension, diabetes, and obesity in the adult population of Morocco: how to avoid "over"- and "under"-diagnosis of CKD. Kidney Int. 2016;89(6):1363-71. https://doi.org/1 0.1016/j.kint.2016.02.019

\section{Publisher's Note}

Springer Nature remains neutral with regard to jurisdictional claims in published maps and institutional affiliations.

Ready to submit your research? Choose BMC and benefit from:

- fast, convenient online submission

- thorough peer review by experienced researchers in your field

- rapid publication on acceptance

- support for research data, including large and complex data types

- gold Open Access which fosters wider collaboration and increased citations

- maximum visibility for your research: over $100 \mathrm{M}$ website views per year

At $\mathrm{BMC}$, research is always in progress.

Learn more biomedcentral.com/submissions 